\title{
Microencapsulation of Extracts from Corn Hair: A Study on Drug Release and Anticancer Activity
}

\author{
Prajakta Kulkarni ${ }^{1, ~ *, ~ M a d h u m i t a ~ T a w r e ~}{ }^{1}$, Mahesh Dere ${ }^{2}$, Ayesha Khan ${ }^{1,2, *}$ \\ ${ }^{1}$ Institute of Bioinformatics \& Biotechnology, Savitribai Phule Pune University, Pune, India \\ ${ }^{2}$ Department of Chemistry, Savitribai Phule Pune University, Pune, India
}

\section{Email address:}

prajaktakulkarni27@gmail.com (P. Kulkarni), meetum1@gmail.com (M. Tawre), maheshdere11@rediffmail.com (M. Dere), ayesha.khan@unipune.ac.in (A. Khan)

${ }^{*}$ Corresponding author

\section{To cite this article:}

Prajakta Kulkarni, Madhumita Tawre, Mahesh Dere, Ayesha Khan. Microencapsulation of Extracts from Corn Hair: A Study on Drug Release and Anticancer Activity. Journal of Drug Design and Medicinal Chemistry. Vol. 7, No. 1, 2021, pp. 12-22. doi: 10.11648/j.jddmc.20210701.13

Received: February 10, 2021; Accepted: March 19, 2021; Published: March 30, 2021

\begin{abstract}
Corn silk contain inherently substantial flavonoid that contribute to its antioxidant and anticancer activity. The objective of the present study was to fabricate a system for efficient delivery of the anticancer compounds using microencapsulation technique. Methanolic corn silk extract was microencapsulated in the polymer Poly (d,1-lactide-co-glycolide) - PLGA using the solvent extraction method. The physicochemical properties such as size, morphology and physical state of free and encapsulated microparticles were measured by dynamic light scattering, scanning electron microscopy (SEM) and transmission electron microscopy (TEM). The in vitro release of compounds were studied and quantified using High Performance Liquid Chromatography (HPLC). Spherical and relatively small $(\mathrm{d}=485.9)$ polymeric microparticles were obtained containing flavonoids with encapsulation efficiency (EE) of 60.66\%. In vitro release profile exhibit a slow, sustained release and follows the first order kinetic with release rate $3.34 \times 10^{-3} \mathrm{~m}^{-1} \mathrm{~s}^{-1}$. The release characteristics data showed that the drug is released from the microsphere even after $108 \mathrm{~h}$. For in vitro cell-based assays, the MTT cell viability assay was performed on HeLa, NIH 3T3 cell lines while cellular uptake of the drug was studied using fluorescence microscopy. Fluorescence studies confirm drug uptake by the cells within $24 \mathrm{~h}$ of treatment. For confirmation of mode of cell death Flow Cytometry and DNA ladder assay was performed. The blank polymeric microparticles were non-toxic to cell while, the drug loaded microparticles exhibit apoptic cell death. Thus an efficient delivery system is achieved after encapsulation, that provides protection and controlled release of the bioactive compounds.
\end{abstract}

Keywords: Anticancer, Flavonoids, PLGA, Microencapsulation, Drug Release, Apoptosis

\section{Introduction}

Cancer is a heterogeneous disease triggered by irreversible impairment of cellular homeostasis and function. The uncontrolled cell growth and differentiation along with loss of apoptotic functions lead to massive expansion in neoplastic cells populations [1, 2]. Internal factors such as lack of apoptic function, genetic mutations, oxidative stress and hypoxia, while excessive exposure to ultraviolet rays radiations, population, smoking and stress are the external factors [3]. There are several technique used for cancer treatment such as chemotherapy, surgery, radiations therapy and immunotherapy [4-6]. Chemotherapy is one of the most effective treatments for cancer but the efficacy of chemotherapy treatment is limited and severe drug related side effects, prolonged chemotherapy treatment weakens the immunological defense system of the body and leaves patients susceptible to other disease and infections. Surgery is the least harmful conventional form of cancer treatment but not for all type of cancer treatment $[7,8]$. Radiation therapy has also a number of potential harmful side effects such as weakened resistance to other diseases and the potential to be carcinogenic itself [9]. Chemoprevention is a rapidly growing area of oncology, which focus on the prevention of cancer using naturally occurring or synthetic agent [10-13]. There are increasing numbers of studies on the identification of novel sources of bioactive compound to prevent cancer. Bioactive 
compounds are of natural origin, particularly from a dietary source. From ancient times plants has been used in the treatment of a number of forms of cancer and they provide leads for the development of potential novel agents $[14,15]$. Corn silk is a well-known traditional functional food and Chinese herbal medicine. Corn silks are fine, soft threads 4-8 inches long, cultivated in warm climate. It is medicinally used as a mild stimulant, diuretic, demulcent of uric acid and chronic cystitis in the bladder irritation of uric acid, phosphatic gravel and Gonorrhea [16]. Corn silk exhibits various pharmaceutical activity like antioxidant [17-20], anti-diabetic [21, 22], antibiotic [23] and antitumor activity [24]. Several studies have revealed that Corn silk consists of polyphenolic compound such as flavonoids, chlorgenic acid, p-coumaric, ferulic acid, saponins, phytosterols, volatile oil, fixed oil, resin, sugar, allantoin, tannin and minerals [25-29].

Flavonoids in their natural form get absorbed poorly in the intestine. They are degraded extensively by the intestinal microorganisms and/or enzymes to form different metabolites. $[30,31]$. Thus direct consumption of flavonoids leads to poor bioavailability, poor permeability, instability and extensive first-pass bioavailability of flavonoids. While encapsulation helps to protect the trapped biological material against oxidation, isomerization and degradation. These techniques increases the shelf life of material over a period of time and control/sustained delivery of functional substances when ingested in the body [32].

Thus targeted drug delivery reduces the toxic side effects to normal cells and increases the delivery of such drug to tumor tissue [33]. Encapsulation in Poly(lactic-co-glycolic acid) (PLGA) (Figure 1) has been approved by the US Food and Drug Administration (FDA) with a wide therapeutic efficacy and easy availability. The controlled release of drug delivery system provides drug release at a controlled rate and maintains the overall therapeutic concentration of drug in the body [34-38].

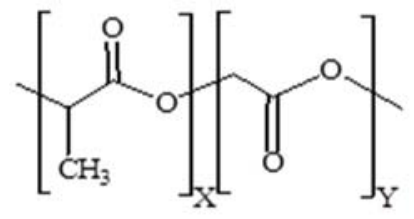

Figure 1. Structure of Poly lactic-co-glycolic acid (PLGA).

In the present study we intend to microencapsulate the flavonoid compounds extracted from corn hair in a biocompatible PLGA polymer, thereby creating a system for efficient drug delivery, which may simultaneously help shield the normal cells from the cytotoxic drug.

\section{Materials and Methods}

\subsection{Materials}

Corn hair was available from local market (Pune, Maharashtra). Chloroform $\left(\mathrm{CHCl}_{3}\right)$, methanol $(\mathrm{MeOH})$, ethyl acetate, acetonitrile, isopropyl alcohol (IPA), ethanol
$\left(\mathrm{C}_{2} \mathrm{H}_{5} \mathrm{OH}\right)$ dimethyl sulfoxide (DMSO), 2,2',2",2"'-(ethane-1,2- diyldinitrilo) tetraacetic acid (EDTA), sodium chloride $(\mathrm{NaCl})$ were obtained from Spectrochem. 85:15 Poly (D, L-lactide-co-glycolide) (PLGA) (viscosity $=$ $0.28 \mathrm{dL} / \mathrm{g}$ in $\mathrm{CHCl}_{3}$ @ $30^{\circ} \mathrm{C}$ ) was obtained from Sigma-Aldrich, methyl ethyl ketone (MEK) was available from sisco research laboratories pvt. 1td, India. (Dulbecco's Modified Eagle's Medium) DMEM, Fetal Bovin serum (FBS), $0.1 \%$ antibiotic solution, polyvinyl alcohol (PVA) were obtained from Hi Media laboratories pvt. Ltd. India. ApoBRdU Tunel Kit was procured from Invitrogen Lab. Standard compounds were obtained from Sigma Aldrich. The phosphate buffer saline (PBS) ( $\mathrm{pH} 7.4$ ), sodium Acetate, paraformaldehyde, hematoxylin stain, eosin, Xylene, Agarose gel, Ethyl bromide, Tris borate EDTA (TBE), 3-(4,5-dimethylthiazol-2-yl)-2,5-diphenyltetrazolium bromide (MTT) buffer, Lysis buffer, Proteinase k solution, Tris HCL, SDS, TE buffer was procured from Sigma Aldrich. High quality Milli-Q water purified in system (Millipore Elix) was used in all experiments.

\subsection{Methods}

\subsubsection{Extraction of the Bioactive Compounds from Corn Hair}

Corn hairs were collected from the local market in Pune, Maharashtra. Corn hairs were dried at $50^{\circ} \mathrm{C}$ in oven for overnight. The bioactive compound from dried corn hairs were extracted in the methanol (100 gm dried powder) using soxhlet extraction method. The methanolic extract was concentrated at $40^{\circ} \mathrm{C}$, under vacuum by using a rotatory evaporator (Rotavapor R-210, Buchi, Switzerland). The concentrated extract was stored at $4^{\circ} \mathrm{C}$ for further use.

\subsubsection{TLC (Thin Layer Chromatography) Profiling of Compound Extracted from Corn Hair}

The concentrated corn hair extract was spotted on silica gel 60 F254, eluted with Ethyl acetate: n-Hexane (4:6). In Lane 1: methanolic extract (Batch 1), Lane 2: Mixture of standard such as Luteolin, Apimaysin, Maysin, Rhamnosyl isoorientin and Rhamnosyl Maysin with detection at $254 \mathrm{~nm}$., Lane 3: methanolic extract from batch 2 .

\subsubsection{Preparation of Polymeric Microparticles}

PLGA microparticles were prepared by solvent extraction method with minor modification using a previously described protocol [39]. PLGA (100 mg) was dissolved in $2.5 \mathrm{~mL}$ of methyl ethyl ketone (MEK) under magnetic stirring (REMI 5 $\mathrm{MLH}$ Magnetic Stirrer) for $2 \mathrm{~min}, 1000 \mathrm{RPM}$, at $25^{\circ} \mathrm{C}$. The resulting PLGA solution was then slowly added to a $2 \%$ PVA aqueous solution using a syringe, during addition the solution of $2 \%$ PVA was stirred using magnetic stirring at 1000 RPM for 2 min to produce an $\mathrm{O} / \mathrm{W}$ emulsion. After 2 minutes, the emulsion was transferred into $30 \mathrm{~mL}$ of $0.5 \%$ PVA aqueous solution and stirred to $1000 \mathrm{RPM}$ for 1 hour at $25^{\circ} \mathrm{C}$. The entire solution was again transferred into $70 \mathrm{~mL}$ of $0.5 \%$ PVA aqueous solution and stirred to $1000 \mathrm{RPM}$ for 3 hour at $25^{\circ} \mathrm{C}$. The microcapsules formed were filtered and washed thrice 
with distilled water and centrifuged at $7000 \mathrm{rpm}$ for 10 minutes at room temperature, the pellet was resuspended in distilled water at $4{ }^{\circ} \mathrm{C}$ and then stored for $12 \mathrm{~h}$ at $-20^{\circ} \mathrm{C}$ and further freeze dried at $-70^{\circ} \mathrm{C}\left(10^{-3}\right.$ Torr $)$ for $48 \mathrm{~h}$ using a commercial freeze dryer (Thermo Electron Corporation Freeze Dryer). The lyophilized microparticles dispersion was stored at $4^{\circ} \mathrm{C}$ until further use. To prepare flavonoid-PLGA loaded microparticles, flavonoids extracted from corn hair were dissolved into the PLGA-MEK solution prior to microparticle synthesis (Drug-loaded microparticles).

\subsubsection{Preparation of Calcium Alginate Beads}

The concentrated corn hair crude methanolic extract $(2$ $\mathrm{mL}$ ) was added to a $10 \mathrm{~mL}$ of $1 \%$ sodium alginate solution prepared in distilled water. The mixture of crude methanol extract and $1 \%$ sodium alginate solution was added drop-wise into a beaker containing $0.75 \%$ of calcium chloride solution. Perfectly spherical beads of calcium alginate were obtained, spherical beads were subsequently strained and washed with distilled water and stored at $4{ }^{\circ} \mathrm{C}$. Similarly, sodium alginate blank beads were prepared without addition of corn hair crude methanolic extract. [40]

\subsection{Characterization}

\subsubsection{Microscopic Examination}

The microparticles were observed using the Light microscope and Fluorescent microscopes (HB050 Ziess Axio Scope A1) using filter FS3 with excitation wavelength at 340 $\mathrm{nm}$. $50 \mu \mathrm{l}$ of sample solution was prepared in distilled water and used for the analysis.

\subsubsection{Morphology}

The morphology of the microparticles was studied by Scanning Electron Microscope (SEM) (JEOL JSM-7600F Field Emission Scanning Electron Microscope (IITB) and FEI Quanta 200 3D Dual Beam ESEM with EDAX (NCL, Pune). Microparticles suspended solution in distilled water coated with platinum using Autofine Sputter Coater with gold particles and then observed under high vacuum conditions with an electron microscope and the morphology of the microparticle was also studied by Tunnelling Electron Microscope (TEM) (TECNAI G ${ }^{2}$, FEI, NCL, Pune).

\subsubsection{Particle Size and Polydispersity Index (PI)}

The mean particle diameter and polydispersity index (PI) of the microparticles were determined by dynamic light scattering (90 Plus Particle Size Analyzer, Brookhaven Instruments Corporation). The sample were suspended in distilled water and sonicated (LABSONIC $® \mathrm{M} 230 \mathrm{~V} / 50 \mathrm{~Hz}$, Sartorius) for 5 minutes to ensure the number of particle counted per second was within the range of instrument sensitivity. Measurements were made at $90^{\circ}$ angle for $3 \mathrm{~min}$ at $25^{\circ} \mathrm{C}$.

\subsubsection{Percentage Yield}

The percentage yield was determined by calculating the weight of microcapsules and the total expected weight of drug and polymer by using the following formula.
Percentage $(\%)$ Yield $=\frac{\text { Weight of the microspheres obtained X } 100}{\text { Total weight of drug }+ \text { polymer }}$

\subsubsection{Encapsulation Efficiency}

Drug Entrapment Efficiency (EE) was determined by High Performance Liquid Chromatography (HPLC) technique (LC-6AD Shimadzu Liquid Chromatography). The microparticles were dissolved in a certain volume of methyl ethyl ketone (MEK). The solution was placed in a desiccator for complete evaporation of MEK, after which acetonitrile / sodium acetate $(\mathrm{pH} 4)$ solution was added and centrifuged (SPINWIN MC-02, TARSONS). The drug content in samples was analyzed using reverse phase HPLC [Mobile phase: Acetonitrile: water (0.1\% Formic acid) $90: 10]$ at $550 \mathrm{~nm}$. The flavonoid content remaining within the microparticles was calculated from the actual amount of the drug present in the polymeric carrier relative to the total amount of drug added. The Drug Entrapment Efficiency (EE) of the flavonoids was determined as follows.

$$
\mathrm{EE}(\%)=\frac{\text { Actual amount of the drug present }}{\text { Total amount of drug loaded }} \times 100
$$

\subsection{Drug in Vitro Release from Microparticles and Drug Release Kinetics}

The flavonoids loaded microparticles were incubated in phosphate buffer saline (PBS, $\mathrm{pH}$ 7.4) in centrifuge tubes and magnetically stirred at constant speed in a water bath (Constant temperature Bath PP1 UniX96, Bio Technics India) maintained at $37^{\circ} \mathrm{C}$. This helps to emulate the conditions present in tissues. Aliquots collected at fixed time points were centrifuged at $7000 \mathrm{rpm}$ at $37^{\circ} \mathrm{C}$ for 8 minutes and replaced by fresh phosphate buffer. The amount of flavonoids released from the microparticles was monitored at $2 \mathrm{~h}, 4 \mathrm{~h}, 6 \mathrm{~h}, 8 \mathrm{~h}$ and $168 \mathrm{~h}$ until 7 days by the HPLC technique with solvent system chloroform, ethyl acetate and methanol (4:1:5). The in vitro drug released from the polymeric microparticle was quantified using the peak area from the HPLC curve. The amount of drug released was fitted to a kinetic plot.

\subsection{Biological Systems in Vitro Studies}

\subsubsection{Culture and Maintenance of Mammalian Cell Lines}

The cell lines HeLa and NIH3T3 were obtained from National Centre for Cell Sciences Repository, University of Pune, Pune. The cells were maintained in DMEM media, with $10 \%$ FBS and $0.1 \%$ antibiotic solution at $37^{\circ} \mathrm{C}$ in the steri-cycle $\mathrm{CO}_{2}$ incubator (Thermo Electron Corporation) with HEPA Class 100 filters at $5 \% \mathrm{CO}_{2}$.

\subsubsection{Revival Protocol for HeLa Cell Lines}

Cell lines were thawed after removing from $-70^{\circ} \mathrm{C}$. A mixture of $500 \mu \mathrm{l}$ of cells and $500 \mu \mathrm{l}$ growth medium was added and centrifuged at $5000 \mathrm{rpm}$ for 5 minutes. After 5 minutes $800 \mu \mathrm{L}$ of supernatant liquid was discarded and fresh $800 \mu \mathrm{L}$ of growth medium was added. The $200 \mu \mathrm{L}$ pellet was made to a volume of $1 \mathrm{~mL}$. This solution was added into a T-flask along with $9 \mathrm{~mL}$ growth medium and incubated at $37^{\circ}$ $\mathrm{C}$ in the $\mathrm{CO}_{2}$ incubator. 


\subsubsection{Preparation of Samples for Cell Line Testing}

The flavonoids extracted from corn hair were encapsulated into the PLGA polymeric microparticle, washed with distilled water and stored at $4{ }^{\circ} \mathrm{C}$. Just before addition the microparticles were centrifuged and re-suspended in sterile conditions in filter-sterilized PBS. This solution was kept under UV for 10 minutes. After 10 minutes the solution was diluted appropriately and added in the wells.

\subsubsection{Cell Growth Inhibition}

The drug-loaded and empty microparticles were suspended in filter-sterilized PBS and added to the cells seeded in 96-well plates and 24-well plates. Optical microscopic technique was used to observe the cell death and cell morphology changes [41].

\subsubsection{Cell Uptake Assay}

To investigate the in vitro cellular uptake of the microparticles, the intrinsic fluorescence of the flavonoids was used. Coverslips were sterilized and kept in 6-well plates. HeLa cells were cultured in these plates for 24 hours, therefore grew on the pre-laid coverslips before addition of medium containing fluorescent microparticles, followed by incubation for another $24 \mathrm{hrs}$. The drug release from the microparticle and internalization within the cell were studied by fluorescence microscope [42].

\subsection{Staining of Cells for Detection of Changes in Morphology}

After the culture of HeLa cells on coverslips for $24 \mathrm{~h}$ and incubation after treating with microparticles for another $24 \mathrm{~h}$, the treated coverslips were transferred into another 6- well plate, where the cells were fixed with $1 \%$ paraformaldehyde. Next, hematoxylin stain was added for 3-5 minutes then the coverslip was washed with PBS and dried. Next, 0.4\% Eosin stain was added for 2-5 minutes and coverslips were washed with PBS to remove excess stain. The coverslip was dipped in alcohol and allowed to dry. After drying the coverslip was dipped in xylene and mounted using DPX. The images were captured in a Carl Zeiss Axio Scope A1 fluorescent microscope with filter set no. FS3 excitation at $340 \mathrm{~nm}$ [43].

\subsection{Quantification of Cell Death via MTT Assay}

The anticancer activity of the free and encapsulated flavonoids were evaluated on cancerous (HeLa) and noncancerous (NIH3T3) cell by following established protocols [44]. HeLa cells and NIH3T3 cells were seeded in 96-well plates and treated with free and encapsulated flavonoids microparticles suspended in PBS. Appropriate controls with DMEM medium and only PBS were taken. The solution of $5 \mathrm{mg} / \mathrm{mL}$ MTT was dissolved in PBS and the solution were filter-sterilized using a syringe filter. After incubation for the stipulated time, $20 \mu \mathrm{l}$ of MTT solution was added to each well. The plate was incubated for $2 \mathrm{~h}$ in the $\mathrm{CO}_{2}$ incubator. After incubation the media was removed and $200 \mu \mathrm{l}$ of DMSO added to each well to dissolve the crystals. The plate was put into the incubator at $37^{\circ} \mathrm{C}$ for 5 minutes.
Absorbance was measured at $540 \mathrm{~nm}$ and $620 \mathrm{~nm}$ on plate reader (ELISA Plate reader-SpectraMax M5 SoftMax ${ }^{\circledR}$ Pro5, Molecular Devices). The anticancer activity was calculated for $24 \mathrm{~h}, 48 \mathrm{~h}, 72 \mathrm{~h}$ and $96 \mathrm{~h}$.

\subsection{DNA Ladder Assay}

The apoptosis of free and encapsulated microparticles was estimated by the DNA ladder assay, adapting our system to the previous established protocols [45]. HeLa cells were plated on 6-well plates with control i.e. no microparticles were added, free and encapsulated flavonoids microparticles. For the DNA extraction the HeLa cells were trypsinised, centrifuged and put in microfuge tubes. The suspension was resuspended in 20 $\mu 1$ Lysis buffer (Lysis Buffer: $50 \mathrm{mM}$ Tris-HCL (pH 8.0), 10 $\mathrm{mM}$ EDTA, $0.5 \%$ SDS, $0.5 \mathrm{mg} / \mathrm{mL}$ proteinase $\mathrm{K}$ added freshly on ice. $5 \mu$ proteinase $\mathrm{K}$ solution was added and the solution was mixed gently to ensure complete lysis. Suspension was incubated at $55^{\circ} \mathrm{C}$ for an hour. The cell debris was pelleted out and $5 \mu 1$ RNase A was added to the separated supernatant. The sample was incubated for another hour at $55^{\circ} \mathrm{C}$. A brief spin was given to remove any other cell debris and the supernatant was collected. $20 \mu 1,5 \mathrm{M} \mathrm{NaCl}$ was added to the supernatant and $120 \mu \mathrm{l}$ isopropanol was added to this. The tubes were kept at $-20^{\circ} \mathrm{C}$ for overnight. The tubes were spun at $14000 \mathrm{x} \mathrm{g}$ for 10 minutes. The supernatant was discarded and the pellets were left to air dry. $20 \mu \mathrm{l}$ TE buffer was added to the tubes. Agarose Gel Electrophoresis (BioEra Life Sciences Pvt. Ltd) was carried out on 1.5\% Agarose gel (with EtBr) at $150 \mathrm{~V}$, in TBE buffer. The gel was visualized and image was captured using Alpha Innotech Multimager II Alphamager ${ }^{\circledR} \mathrm{HP}$.

\subsection{Protocol for Flow Cytometry}

For preparation of cells for FACS, the APO-BrDUTM TUNEL Assay kit from Invitrogen was used. HeLa cells were plated on 6-well plates. Microparticles were added to specific wells. The wells were designated as unstained control, control (without any treatment), only PBS, free drug, empty microparticles and drug-loaded microparticles. The plates were incubated for $24 \mathrm{~h}$ and the cells were fixed according to the manufacturer's protocol.

\subsection{Protocol for Cell Fixation}

Cells were trypsinized and suspended in $0.5 \mathrm{~mL}$ PBS. The cell suspension was added to $5 \mathrm{~mL} 1 \%$ paraformaldehyde (w/v) in PBS and placed on ice for 15 minutes. The cells were centrifuged at $300 \mathrm{xg}$ for 5 minutes and the supernatant was discarded. The cells were washed with $5 \mathrm{~mL}$ PBS and pelleted again by centrifugation. The cells were re-suspended in 0.5 $\mathrm{mL}$ PBS and added to ice-cold $70 \%$ ethanol (v/v). The cells were stored at $-20^{\circ} \mathrm{C}$ till use. The cells get stained as per given in the protocol in the Invitrogen APO-BrdUTM TUNEL Assay kit. The FACS analysis data was acquired using BD FACS Calibur. The data was analyzed using the Cell Quest Pro software. 


\section{Result}

\subsection{TLC Profile of Compounds Extracted from Corn Hair}

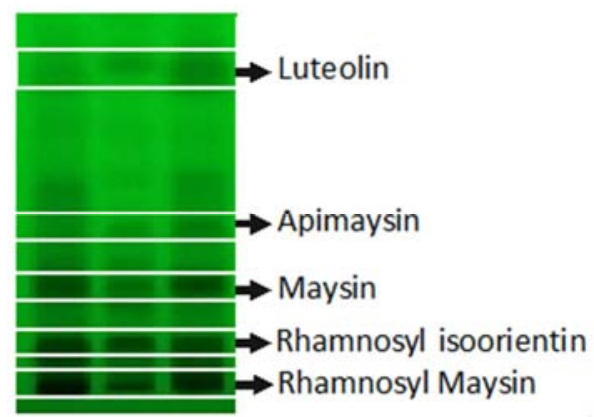

Figure 2. Corn silk extract separated on silica gel 60 F254, eluted with Ethyl acetate: n-Hexane (4:6) Lane 1: methanolic extract (Batch 1) Lane 2: Mixture of standard with detection at $254 \mathrm{~nm}$.; Lane 3: methanolic extract batch 2.

\subsection{Morphological and Electrical Properties of Microparticles}

The functional performance of the microparticles based delivery system depends on the physiochemical properties such as size, morphology and physical state of the microparticles [46, 47]. The mean particle diameter and polydispersity index (PI) of the polymeric microparticles by DLS technique was $485.9 \mathrm{~nm}$ with narrow distribution $(\mathrm{PI}=0.186)$ were obtained. The electron microscopic images studies (SEM and TEM) confirmed that the free and encapsulated PLGA microparticles were relatively small spheres with the similar dimensions. SEM studies showed that Figure 3 (A) and (B) all particles formed were spherical with particle diameter $0.3-1 \mu \mathrm{m}$. The TEM image showed that empty microparticles are hollow Figure 4 (A), while the drug loaded microparticles are packed with the drug. The Figure 4 (B) showed that the polymer coat was dissolved from the outside when in contact with water due to the hydrolysis of PLGA resulting the release of the drug to the outside medium and also confirmed that the particle size around 0.3 to $0.5 \mu \mathrm{m}$ Figure $4(\mathrm{C})$ and (D).

The PI values $(\mathrm{PI}=0.186)$ indicated that the free and loaded microparticles obtained by solvent extraction method were homogenous and that the method employed was reproducible and stable [48]. DLS studies showed that mean particle diameter was around $485.9 \mathrm{~nm}$ Figure 5 (A). The multimodal distribution curve Figure 5 (B) showed that two or more modes of populations present, this is because the sample was not sieved prior to taking the reading. Therefore there was more than 2 size of particle getting formed in high frequency. The mean diameter given by this distribution is $402.4 \mathrm{~nm}$. Figure 5 (C) showed the lognormal size distributions curve was bell shaped with median diameter at $225.5 \mathrm{~nm}$. The drug entrapment was confirmed by fluorescence imaging of the microparticles Figure 6 (A) and (C). Under filter FS3 with excitation wavelength at $340 \mathrm{~nm}$ showed the drug entrapped in PLGA microparticles Figure 6 (B) and (D). Empty microparticles exhibited no fluorescence while drug loaded microparticles show bright fluorescence.

\subsection{Encapsulation Efficiency}

The Encapsulation Efficiency (EE) of flavonoids with the PLGA microparticles was $60.66 \%$. These results were lower than the expected due to the fact that some flavonoids may have been present with surrounding aqueous phase because of concentration of PVA used, which increase solubility of flavonoids in water and thus more flavonoids molecule may partition out rapidly to the aqueous phase $[49,50]$, thereby decreasing the Encapsulation Efficiency.

\subsection{In Vitro Release Studies}

We investigated the release of flavonoids from PLGA microparticles as a function of $\mathrm{pH}(\mathrm{pH}-7.4)$ with constant stirring in $\mathrm{PBS}$ at $37^{\circ} \mathrm{C}$. The experiment was performed in PBS at $\mathrm{pH} 7.4$, stimulating the $\mathrm{pH}$ conditions in the small intestine (6-7) in the absence of enzyme. The result gives the information about how to understand the protection and release of bioactive flavonoids at $\mathrm{pH} 7.4$ and neutral $\mathrm{pH}$ condition in small intestine.
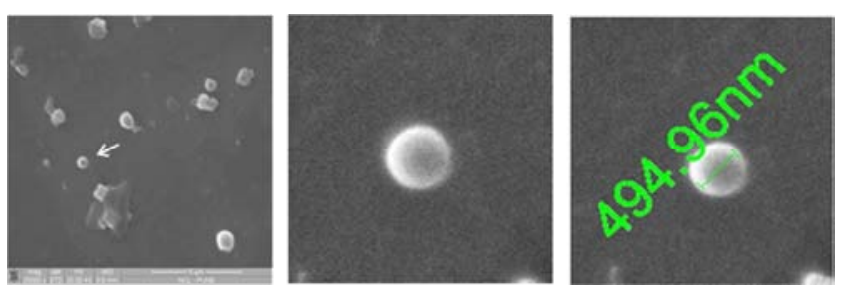

(A)
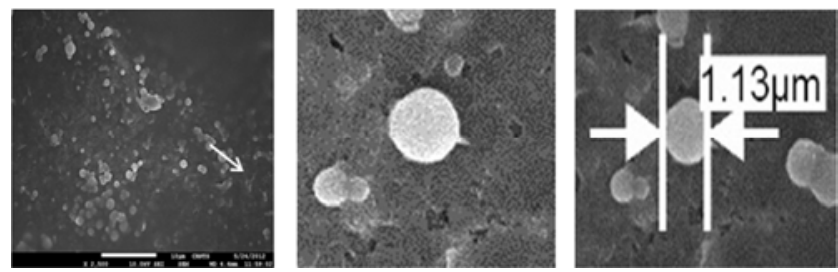

(B)

Figure 3. SEM micrographies (A)-Empty PLGA microparticles, (B)-Drug loaded PLGA microparticle.

There are several methods viz. HPLC, UV-Vis and fluorescence spectroscopy to study the in vitro release profile of flavonoids from polymeric microparticles. The advantages of using HPLC is that this technique allows to monitor in real time, the release of bioactive compounds from the polymeric microparticles using at same time, low amount of sample quantity and with greater accuracy. Table 1 shows the peak area obtained for flavonoids release from PLGA microparticle in PBS buffer (pH 7.4) during a 108 hours' time period. These values were interpolated in curve Figure 7, (Peak area Vs Time) used to determine the flavonoids release during the experimentation time. The in vitro release of flavonoids from PLGA microparticles showed gradual release at longer time up to 48 hours. Graph (Peak area Vs Time) followed the biphasic release of flavonoids release from PLGA microparticle up to 72 hours and then gradual release up to 108 hours. 


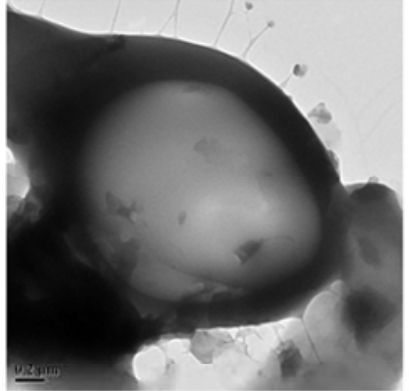

(A)

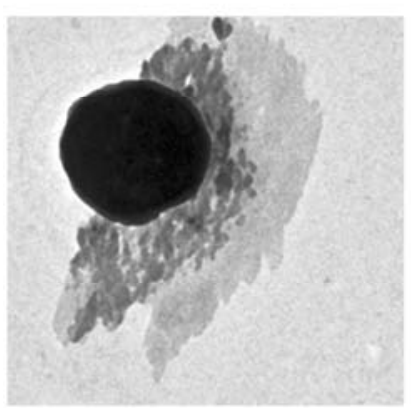

(C)

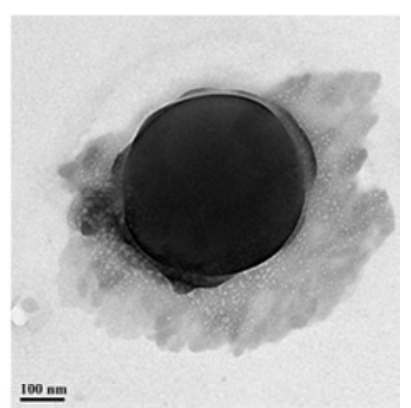

(B)

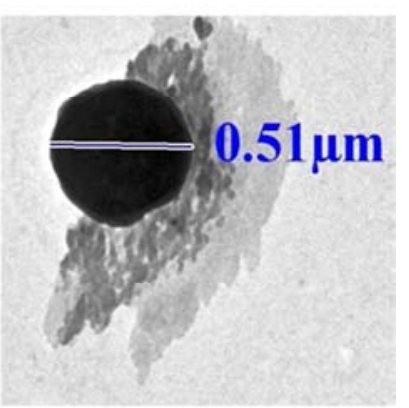

(D)
Figure 4. TEM micrographies (A)-Empty PLGA microparticles, (B)-Drug loaded PLGA microparticle, (C)-Empty PLGA microparticles and (D)-Drug load PLGA microparticle with depict.

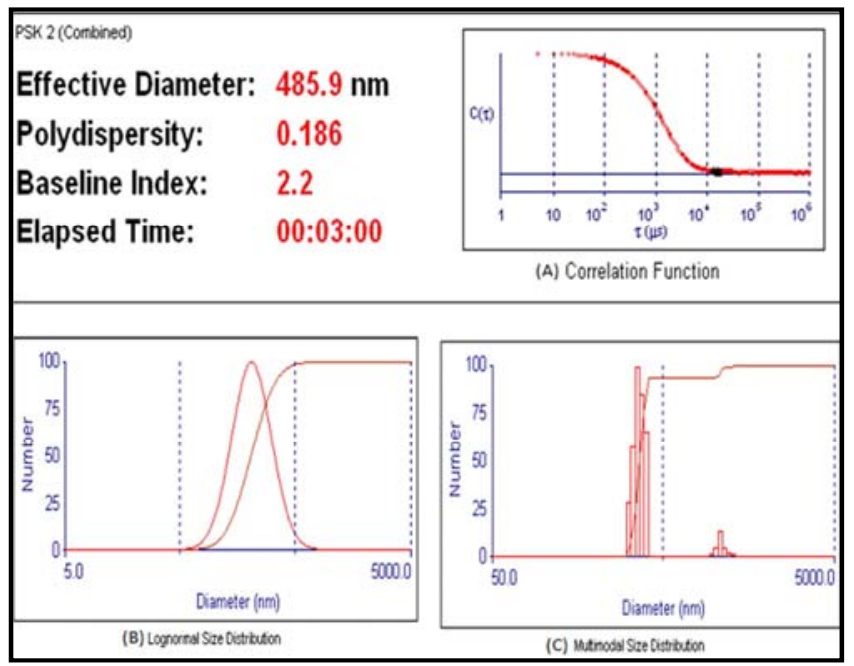

Figure 5. (A)-Mean particle diameter, polydispersity index, (B)-Multimodal size distribution curve and (C)-Lognormal size distribution curve of the PLGA microparticle.

Table 1. HPLC data for in vitro release study in PBS (pH-7.4) at 37 for during 108 hours.

\begin{tabular}{ll}
\hline Time (Hours) & Area \\
\hline 4 & 1191793 \\
8 & 1084756 \\
24 & 1000274 \\
48 & 938726 \\
72 & 87563 \\
96 & 53928 \\
108 & 39271 \\
\hline
\end{tabular}

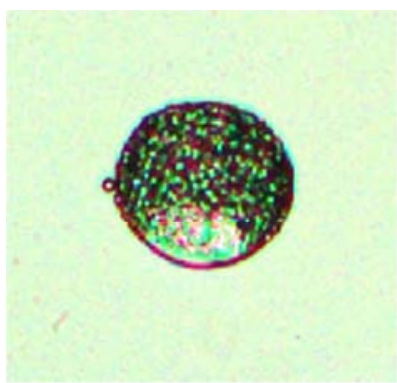

(A)

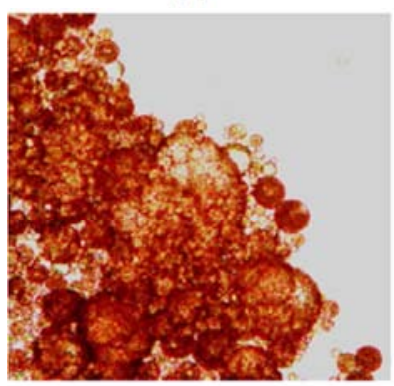

(C)

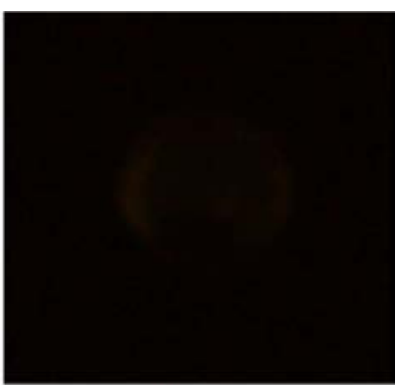

(B)

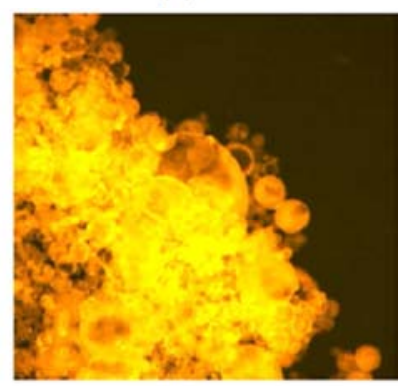

(D)
Figure 6. Microscopic image under bright light and green fluorescence (A)-Empty PLGA microparticle under bright light, (B)-Empty PLGA microparticle under green fluorescence, (C)-Drug loaded PLGA microparticle under bright light, (D)-Drug PLGA microparticle under green fluorescence.

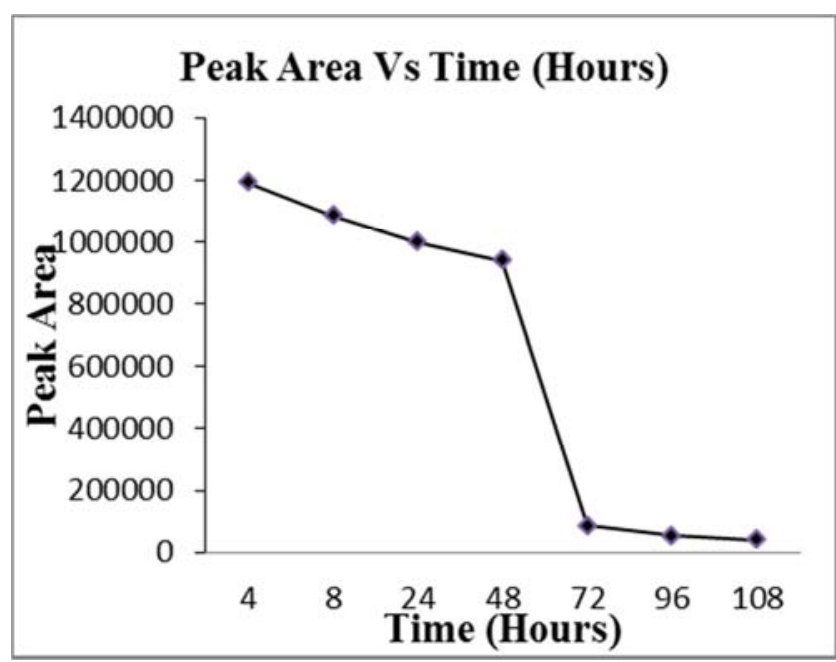

Figure 7. Peak Area of Flavonoids obtained by the release from loaded PLGA microparticles in PBS ( $\mathrm{pH}-7.4)$ at 37 during 108 hours of analysis period by HPLC technique.

\subsection{Drug Release Kinetics}

The release of flavonoids from PLGA microparticles as a function of $\mathrm{pH}$ (7.4) with constant stirring in $\mathrm{PBS}$ at $37^{\circ} \mathrm{C}$ was monitored. The release study gives the information to understand the release kinetics of bioactive flavonoids at neutral $\mathrm{pH} 7.4$ in the small intestine. Figure 9 Shows the concentration of flavonoids released from PLGA microparticles during time period of 6 days. These values were plotted (Conc. $\mu \mathrm{m}$ Vs days) in the software that were used to determine the drug release kinetic during the experimentation time. The result showed that the curve was 
very smooth, fast release on day1 and follows the first order kinetics. There was initial burst on dayl and then the release was slow and sustained over a period of almost a week, the rate of dissolution of the drug from graph was $3.34 \mathrm{x}$ $10^{-3} \mathrm{M}^{-1} \mathrm{~S}^{-1}$. As some authors have claimed the burst release of flavonoids species due to the diffusion of the flavonoids molecules that are dispersed closer to the surface of the PLGA nanoparticles [51-53].

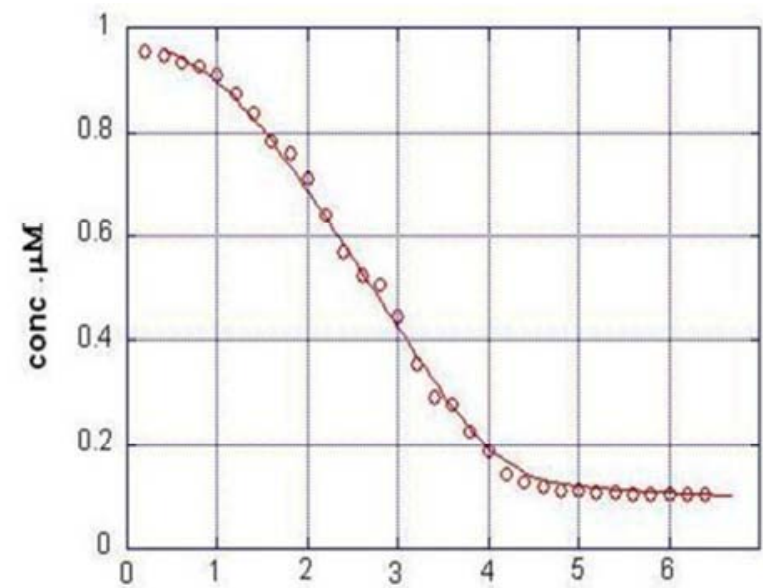

No. of Days

Figure 8. Drug release kinetic curve from PLGA microparticle in PBS (pH-7.4) at 37 by spetrophotometric.

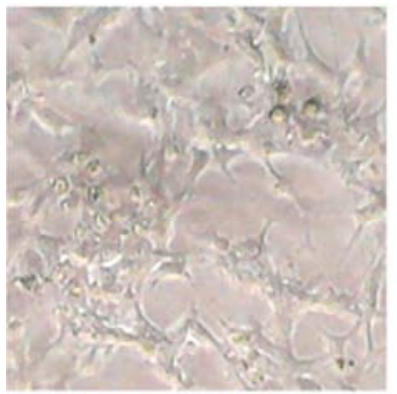

(A) Control

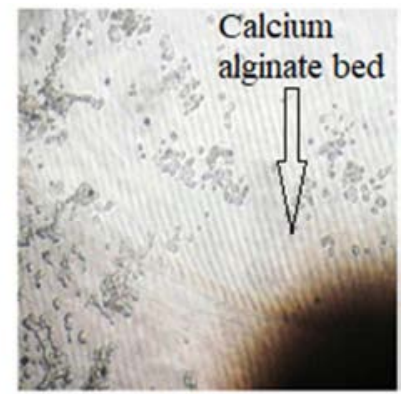

(B) Test
Figure 9. Effect of drug encapsulation on HeLa cells in calcium alginate bead (A)-Treated with empty microparticle, (B)-Treated with drug loaded microparticle.

\subsection{Drug loaded Calcium alginate Beads}

To investigate the ability of free and encapsulated bioactive compounds extracted from corn hair in methanol extract (flavonoids) in PLGA microparticle to affect the cell (HeLa) in calcium alginate bed to leach out across a barrier and subsequently affect cells, the compounds were encapsulated in calcium alginate beads which have a large pore size. The beads were administered on the cells after filtering them and dispersing them in PBS. Figure 9 Shows the changes in the cell number and morphology of cell (HeLa), after the treatment with free and drug loaded bioactive compound on calcium alginate beads. The study showed that cell death occurred as the cell number reduced and the cell morphology was altered.
It also showed that the cell number specifically around the beads reduced indicating that the effective compound leached out of the bead and render cytotoxicity to the cell. Therefore, it was concluded that the drug was stable even inside a coating and able to leach out, to affect the cells.

\subsection{Biological Systemsin Vitro Studies}

\subsubsection{Cell Uptake Assay}

The successfully drug internalization by the cells and release from the microparticles was studied by florescence microscopy using HeLa cells. Figure 10 Shows there was no fluorescence under green filter in control cells viz. empty PLGA microparticles. While the encapsulated microparticles with extract fluoresce using the green filter. The obtained data showed that the drug is efficiently internalized within the cells.

\subsubsection{Cell Growth Inhibition}

The effect of free and drug loaded microparticles on the HeLa cells were observed under a light microscope. Figure 11 shows the cell viability of HeLa cells by free and drug loaded microparticles over a 96 hour time period. Our result showed that cells were healthy and no decrease in the cell numbers was observed in the control cells, cells treated with PBS and cells treated with empty PLGA microparticles. However, the cells treated with drug loaded microparticles exhibit cell death and decreased number of cells. These results suggest that the drug release from drug loaded PLGA microparticles affect cancer cells resulting cell death. The study may be useful to the incorporation of bioactive flavonoids with the aim to inhibit the cancer cell growth in the human body.
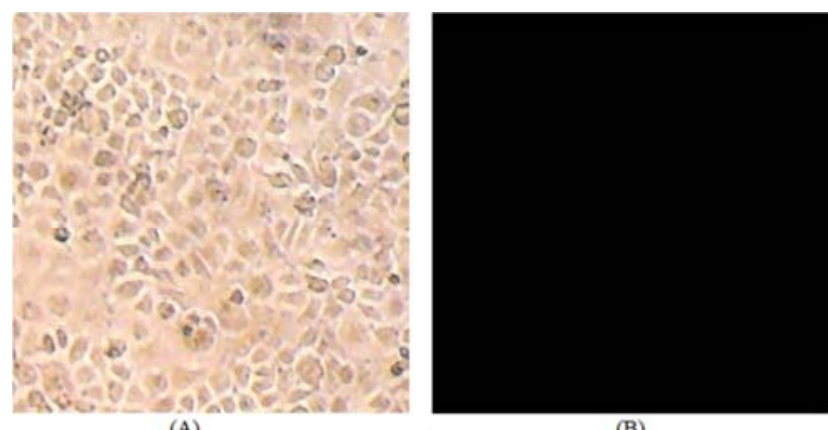

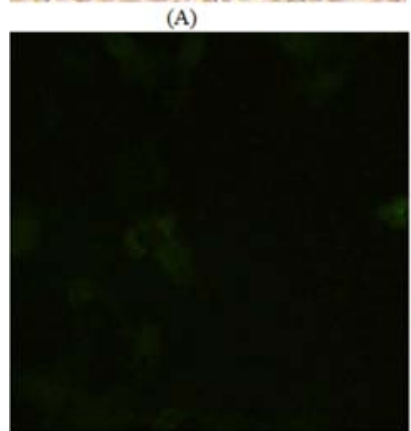

(C)

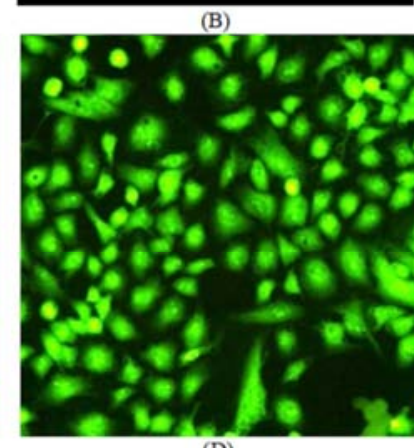

(D)

Figure 10. Fluorescent study of Cellular uptake of drug by PLGA microparticle (A)-Control cells, (B)-Control cells under fluorescence, (C)Empty microparticles, (D)- Drug loaded Microparticles 


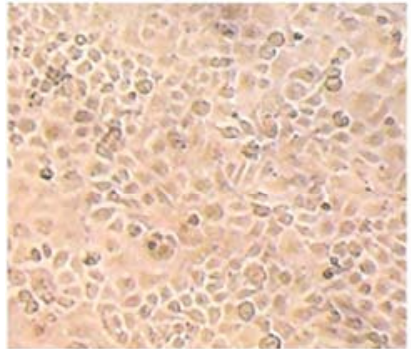

(A)

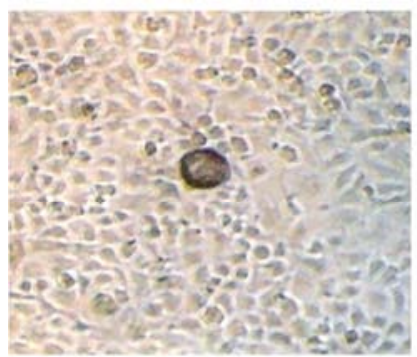

(C)

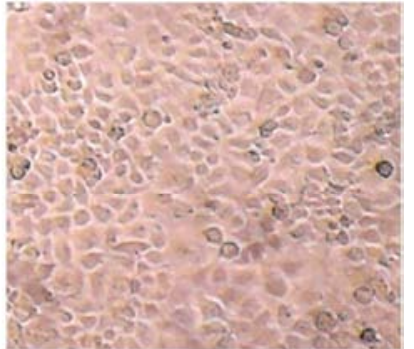

(B)

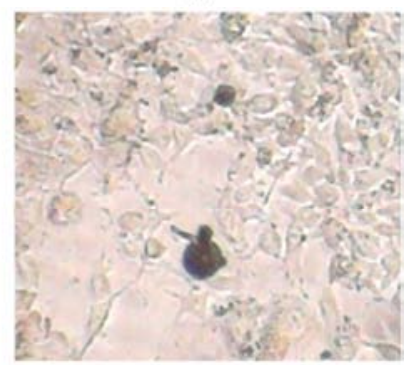

(D)
Figure 11. Light microscopy images for the effect of addition of microparticles to HeLa cells (A)-Control cells, (B)-cells treated with only PBS, (C)-Cells treated with empty microparticles, (D)-Cells treated with drug loaded microparticles.
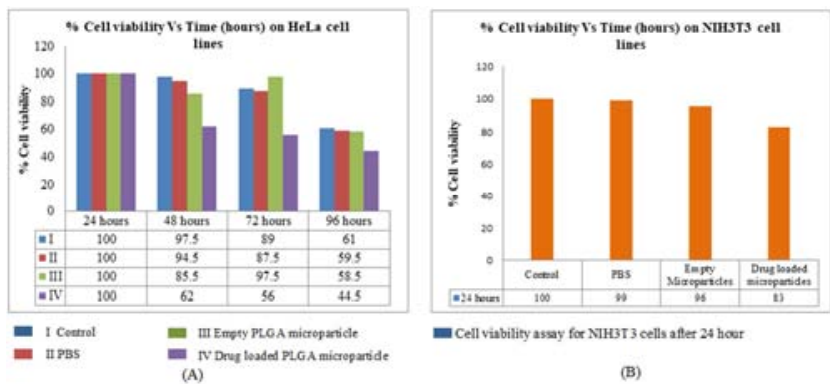

Figure 12. (A)-Cell viability assay on HeLa cell lines at one specific time of experimentation (24, 48, 72 and 96 hours) and (B)-Cell viability assay on NIH3T3 cell lines at 24 hour.

\subsubsection{Cell Toxicity Assay for HeLa Cells}

The cell viability assay for the free and drug loaded PLGA microparticles on the cancerous cell (HeLa) were assessed by the MTT cell viability assay for 24, 48, 72 and 96 hours' time period. Our result showed that the drug loaded microparticles affects to a greater extent on cell survival and cell count rather than the empty PLGA microparticles. The drug loaded microparticles drastically reduced the cell count almost by $50 \%$ in the 24 hours. This can be attributed to the initial burst of the drug up to $4 \mathrm{~h}$ after addition. The cell death remains fairly constant over 48 and 72 hour time period indicating the slow drug release over time. The cell death further reduces after $96 \mathrm{~h}$ of treatment Figure $12(\mathrm{~A})$. The data obtained from the cell toxicity assay were correlated with slow drug release after initial burst studied by drug release from the drug loaded microparticle by HPLC technique. These results suggest that drug loaded PLGA microparticle are suitable for cell toxicity exhibit slow and sustained released of the drug in the biological environment.

\subsubsection{Cell Toxicity Assay for Non-cancerous Cell Line - NIH3T3}

We also evaluated the effect of free and drug loaded PLGA microparticles to the cell death or cell viability assay on non-cancerous cell lines NIH3T3 after the treatment of 24 hour time period. Figure 12 (B). Showed that the \% cell viability of empty and drug loaded PLGA microparticles after 24 hour treatment. Our results suggest that the addition of empty and drug loaded microparticle did not show the significant changes on the cell death or cell viability. Therefore drug loaded PLGA microparticle may be suitable to protect the non-cancerous or normal cells.

\subsubsection{Mode of Cell Death-Cell Staining for Detection of Changes in Morphology}

The cells were then stained with Hematoxylin and Eosin to observe the changes in morphology. Staining after addition of microparticles for $24 \mathrm{~h}$ showed no changes in cell shape or size. This indicated that the cell mode was not necrotic, as the cell structure integrity was intact. This was therefore taken as the indication that the mode of cell death was most likely by apoptosis

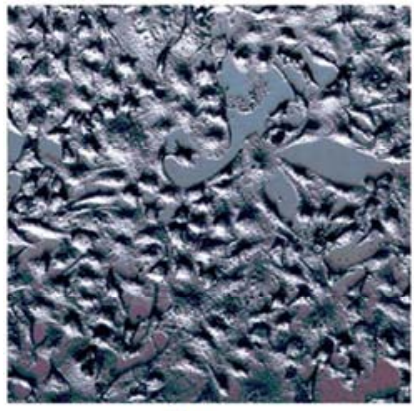

(A)

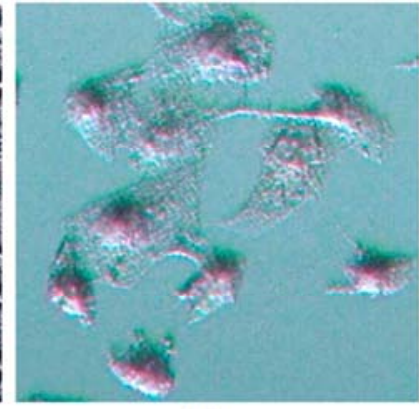

(B)
Figure 13. Cell staining for detection of changes in morphology. The cells were stained with (A)-Hematoxylin (B)-Eosin.

\subsubsection{DNA Ladder Assay}

To show that the mode of cell death is apoptosis, the DNA ladder assay was done. In apoptotic cells, the DNA gets disintegrates into small fragments. These fragments can be detected on the agarose gel to indicate apoptosis. From the agarose gel image it can be seen that there is some shearing of DNA in the wells containing the microparticles showed in Figure 14. This showed that the treatment with microparticles brought about apoptotic cell death.

\subsubsection{Flow Cytometry Analysis for Apoptosis}

The mode of cell death was confirmed using Terminal deoxynucleotide transferase dUTP Nick End Labeling (TUNEL) Assay. During apoptosis, the DNA get fragmented into small parts. In this assay, the enzyme terminal deoxynucleotidyl tranferase (TdT) transfers bromodeoxyuridine triphosphate (Br-UTP) to the ends of the many fragments formed. A fluorescein-labelled antiBrDU antibody is then used to count the fragments. Thus, more intensity of dye means more number of fragments, indicating more amount of apoptotic cell population. Propidium Iodide 
(PI) is also added to the sample, as even PI stains DNA, indicator of apoptosis. Thus, we checked for dual positive population i.e. cells showing both FITC (Fluorescien) and PI staining, which confirmed apoptotic cells.

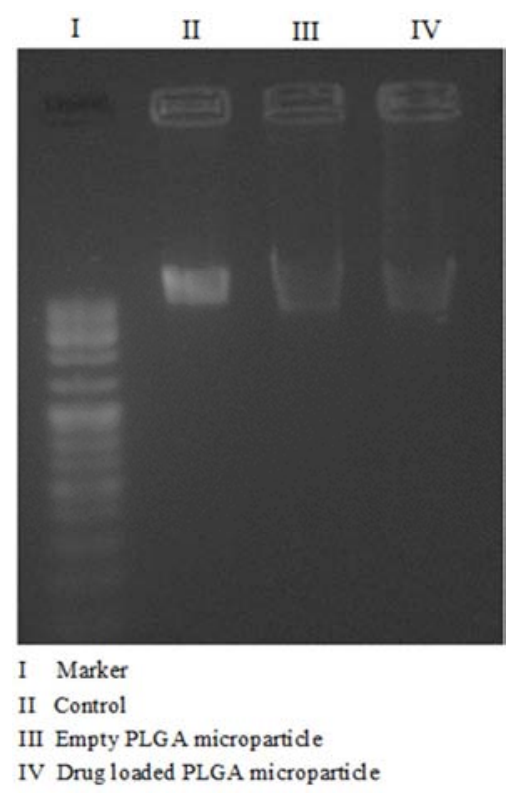

Figure 14. DNA ladder assay for apoptosis of empty and drug loaded PLGA microparticle by gel electrophoresis.
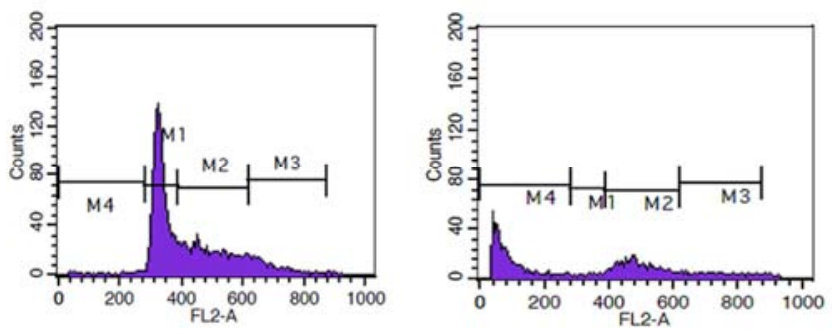

\begin{tabular}{rrrrrrrrrr} 
Marker Left, Right & Events & \% Gated & Total & Mean & Geo Mean & CV & \multicolumn{2}{c}{ Median Peak Ch } \\
\hline All & 0,1023 & 9401 & 100.00 & 94.01 & 410.01 & 394.15 & 29.15 & 353.00 & 320 \\
M1 & 280,386 & 5407 & 57.52 & 54.07 & 329.53 & 328.87 & 6.42 & 326.00 & 320 \\
M2 & 386,618 & 3215 & 34.20 & 32.15 & 490.12 & 485.46 & 13.85 & 484.00 & 446 \\
M3 & $619, \quad 870$ & 712 & 7.57 & 7.12 & 678.92 & 676.98 & 7.77 & 660.00 & 630 \\
M4 & 0. 279 & 79 & 0.84 & 0.79 & 161.41 & 133.67 & 53.64 & 156.00 & 41 \\
Marker & Left, Right & Events & \% Gated & \% Total & Mean & Geo Mean & CV & Median & Peak Ch \\
\hline All & 0. 1023 & 3512 & 100.00 & 35.12 & 321.57 & 208.63 & 76.86 & 349.00 & 41 \\
M4 & 0,279 & 1685 & 47.98 & 16.85 & 88.54 & 77.42 & 58.90 & 70.00 & 41 \\
M1 & 280,386 & 138 & 3.93 & 1.38 & 342.93 & 341.54 & 8.96 & 345.50 & 385 \\
M2 & 386,618 & 1271 & 36.19 & 12.71 & 487.65 & 484.36 & 11.74 & 479.00 & 464 \\
M3 & 619,870 & 385 & 10.96 & 3.85 & 737.07 & 733.62 & 9.69 & 734.00 & 633
\end{tabular}

Figure 15. Histogram showing intensity of PI for (A)-Sample treated with the empty microparticle and (B)-Sample treated with the drug-loaded microparticles.

Furthermore, the difference can also be seen in the intensity of the PI levels. PI levels help us to understand the cell cycle phase the cells were in. The phases were divided into M1, M2, M3 and M4. M4 denoted the phase wherein the apoptotic cells are present. M2 is the synthetic phase, and M3 is the G2/M phase. Thus, an increase in the M4 on a graph of intensity of PI levels (FL2), indicates an increase in the count of apoptotic cells. From the obtained data we can conclude that the more number of apoptotic cells were found in the drug-loaded microparticles sample. This was in coherence with the HPLC data which showed the slow release of the drug.

\section{Conclusion}

Polymeric microparticles prepared by solvent extraction technique using non chlorinated solvent were used to encapsulate, protect and release the bioactive compound extracted from corn hair. Our result showed that flavonoids were successfully encapsulated in PLGA microparticles spherical in shape with $485.9 \mathrm{~nm}$ diameter and $66.60 \%$ encapsulation efficiency (EE), also in vitro release study showed that after initial burst on day first the drug release was slow and followed the first order reaction curve with $3.34 \times 10^{-3} \mathrm{~m}^{-1} \mathrm{~s}^{-1}$ release rate. The drug loaded microparticles were non-toxic to the normal or non-cancerous cell (NIH3T3) and cytotoxic to the cancerous cell (HeLa). Hematoxylin and Eosin staining study investigated that the mode of cell death was apoptotic not necrotic and confirmed by the DNA ladder assay and flow cytometry assay. The flow cytometry result revealed that the cell death was apoptotic and apoptotic population was less in sample treated with empty PLGA microparticle rather than the drug loaded microparticle. Therefore, the release profile method used for the encapsulation of bioactive compound extracted from plant remedies was reproducible and stable for delivery of bioactive compound by targeted, sustained release. This delivery system may be helpful as novel therapeutic system to delay the development of diseases related to the oxidative stress like cancer and diabetic mellitus. In general, our results have important implications for the encapsulation of bioactive compound into the polymeric material for delivery system for human health and wellness.

\section{Conflict of Interest}

All the authors do not have any possible conflicts of interest.

\section{Acknowledgements}

AK acknowledges UGC [F. No. 43-94/2014 (SR)] for MRP project. The authors acknowledge the Institute of Bioinformatics \& Biotechnology, Savitribai Phule Pune University, Pune, India, Department of Chemistry, Savitribai Phule Pune University, Pune, India for providing research support to carry out the research work.

\section{References}

[1] F. H. Igney and P. H. Krammer, "Death and anti-death: tumour resistance to apoptosis.," Nat. Rev. Cancer, vol. 2, no. 4, pp. 277-288, Apr. 2002, doi: 10.1038/nrc776.

[2] E. Safarzadeh, S. S. Shotorbani, and B. Baradaran, "Herbal Medicine as Inducers of Apoptosis in Cancer Treatment," vol. 4, no. Suppl 1, pp. 421-427, 2014, doi: 10.5681/apb.2014.062. 
[3] O. Prakash, A. Kumar, and P. Kumar, "Anticancer Potential of Plants and Natural Products: A Review," no. April 2017, 2013, doi: 10.12691/ajps-1-6-1.

[4] Y. S. Jhanwar, C. Divgi, N. York, and N. York, "Current Status of Therapy of Solid Tumors," pp. 141-151.

[5] V. Guillemard and H. U. Saragovi, "Novel approaches for targeted cancer therapy.," Curr. Cancer Drug Targets, vol. 4, no. 4, pp. 313-326, Jun. 2004, doi: $10.2174 / 1568009043332989$.

[6] S. Antonia, J. J. Mulé, and J. S. Weber, "Current developments of immunotherapy in the clinic," Curr. Opin. Immunol., vol. 16, no. 2, p. 130-136, Apr. 2004, doi: 10.1016/j.coi.2004.01.012.

[7] F. Caponigro, M. Basile, V. de Rosa, and N. Normanno, "New drugs in cancer therapy, National Tumor Institute, Naples, 17-18 June 2004.," Anti-cancer drugs, vol. 16, no. 2. England, pp. 211-221, Feb. 2005, doi: 10.1097/00001813-200502000-00014.

[8] T. J. Miner, "Palliative Surgery for Advanced Cancer: Lessons Learned in Patient Selection and Outcome Assessment," Am. $J$. Clin. Oncol., vol. 28, no. 4, 2005, [Online]. Available: https://journals.lww.com/amjclinicaloncology/Fulltext/2005/0 8000/Palliative_Surgery_for_Advanced_Cancer_Lessons.15. aspx.

[9] M. Elshaikh, M. Ljungman, R. Ten Haken, and A. S. Lichter, "Advances in Radiation Oncology," Annu. Rev. Med., vol. 57, no. 1, pp. 19-31, Jan. 2006, doi: 10.1146/annurev.med.57.121304.131431.

[10] J. J. Smith, P. Tully, and R. M. Padberg, "Chemoprevention: A Primary Cancer Prevention Strategy," Semin. Oncol. Nurs., vol. 21, no. 4, pp. 243-251, 2005, doi: https://doi.org/10.1016/j.soncn.2005.06.009.

[11] M. B. Sporn and K. T. Liby, "Cancer chemoprevention: scientific promise, clinical uncertainty.," Nat. Clin. Pract. Oncol., vol. 2, no. 10, pp. 518-525, Oct. 2005, doi: $10.1038 /$ ncponc 0319 .

[12] D. E. Brenner and A. J. Gescher, "Cancer chemoprevention: lessons learned and future directions," Br. J. Cancer, vol. 93, no. 7, pp. 735-739, Oct. 2005, doi: 10.1038/sj.bjc.6602765.

[13] E. S. Kim and W. K. Hong, "An Apple a Day...Does It Really Keep the Doctor Away? The Current State of Cancer Chemoprevention," JNCI J. Natl. Cancer Inst., vol. 97, no. 7, pp. 468-470, Apr. 2005, doi: 10.1093/jnci/dji103.

[14] J. R. Patil, K. N. Chidambara Murthy, G. K. Jayaprakasha, M. B. Chetti, and B. S. Patil, "Bioactive compounds from Mexican lime (Citrus aurantifolia) juice induce apoptosis in human pancreatic cells.," J. Agric. Food Chem., vol. 57, no. 22, pp. 10933-10942, Nov. 2009, doi: 10.1021/jf901718u.

[15] Q. Hu and Z. Deng, "Protective effects of flavonoids from corn silk on oxidative stress induced by exhaustive exercise in mice," vol. 10, no. 16, pp. 3163-3167, 2011, doi: 10.5897/AJB10.2671.

[16] Grieve M., A Modern Herbal. New York; Dover Publication, 1971.

[17] Z. Maksimović, D. Malencić, and N. Kovacević, "Polyphenol contents and antioxidant activity of Maydis stigma extracts.," Bioresour. Technol., vol. 96, no. 8, pp. 873-877, May 2005, doi: 10.1016/j.biortech.2004.09.006.
[18] Z. A. Maksimović and N. Kovačević, "Preliminary assay on the antioxidative activity of Maydis stigma extracts," Fitoterapia, vol. 74, no. 1, pp. 144-147, 2003, doi: https://doi.org/10.1016/S0367-326X(02)00311-8.

[19] S. Mohsen and A. Ammar, "Total phenolic contents and antioxidant activity of corn tassel extracts," Food Chem. FOOD CHEM, vol. 112, pp. 595-598, Feb. 2009, doi: 10.1016/j.foodchem.2008.06.014.

[20] A. El-Ghorab, K. F. El-Massry, and T. Shibamoto, "Chemical composition of the volatile extract and antioxidant activities of the volatile and nonvolatile extracts of Egyptian corn silk (Zea mays L.).," J. Agric. Food Chem., vol. 55, no. 22, pp. 9124 9127, Oct. 2007, doi: 10.1021/jf071646e.

[21] J. Guo, T. Liu, L. Han, and Y. Liu, "The effects of corn silk on glycaemic metabolism," Nutr. Metab. (Lond)., vol. 6, p. 47, Nov. 2009, doi: 10.1186/1743-7075-6-47.

[22] O. Rau, M. Wurglics, T. Dingermann, M. Abdel-Tawab, and M Schubert-Zsilavecz, "Screening of herbal extracts for activation of the human peroxisome proliferator-activated receptor," Pharmazie, vol. 61, pp. 952-956, Dec. 2006.

[23] A. C. Waiss Jr. et al., "Maysin, a Flavone Glycoside from Corn Silks with Antibiotic Activity Toward Corn Earworm13," $J$. Econ. Entomol., vol. 72, no. 2, pp. 256-258, Apr. 1979, doi: 10.1093/jee/72.2.256.

[24] S. Habtemariam, "Extract of corn silk (stigma of Zea mays) inhibits the tumour necrosis factor-alpha- and bacterial lipopolysaccharide-induced cell adhesion and ICAM-1 expression.," Planta Med., vol. 64, no. 4, pp. 314-318, May 1998, doi: 10.1055/s-2006-957441.

[25] C. A. Elliger, B. G. Chan, A. C. Waiss, R. E. Lundin, and W. F. Haddon, "C-Glycosylflavones from Zea mays that inhibit insect development," Phytochemistry, vol. 19, no. 2, pp. 293297, 1980, doi: https://doi.org/10.1016/S0031-9422(00)81977-9.

[26] M. E. Snook et al., "Levels of maysin and maysin analogs in silks of maize germplasm," J. Agric. Food Chem., vol. 41, no. 9, pp. 1481-1485, Sep. 1993, doi: 10.1021/jf00033a024.

[27] R. S. Sosa A, Rosa EL, Fusca MDR, "Flavonoids and saponins from styles and stigmas of Zea mays L.(Gramineae)," Acta Farm Bonaer., vol. 16, pp. 215-218, 1997.

[28] N. M. Fazilatun N, Zhari I, "Phytochemicals from corn silk (Zea mays)," J Trop Med Plants, no. 2, pp. 189-92., 2001.

[29] M. A. Ebrahimzadeh, F. Pourmorad, and S. Hafezi, "Antioxidant activities of Iranian corn silk," Turkish J. Biol., vol. 32, no. 1, pp. 43-49, 2008.

[30] A. Bilia, B. Isacchi, C. Righeschi, C. Guccione, C. Maria, and M. Bergonzi, "Flavonoids Loaded in Nanocarriers: An Opportunity to Increase Oral Bioavailability and Bioefficacy," Food Nutr. Sci., vol. 05, Jul. 2014, doi: 10.4236/fns.2014.513132.

[31] S. Kumar and A. K. Pandey, "Chemistry and Biological Activities of Flavonoids: An Overview," Sci. World J., vol. 2013, p. 162750, 2013, doi: 10.1155/2013/162750.

[32] J. Jin, G. E. Sklar, V. Min Sen Oh, and S. Chuen Li, "Factors affecting therapeutic compliance: A review from the patient's perspective," Ther. Clin. Risk Manag., vol. 4, no. 1, pp. 269286, Feb. 2008, doi: 10.2147/tcrm.s1458. 
[33] R. S. Solecki, "Shanidar IV, a Neanderthal Flower Burial in Northern Iraq," Science (80-.)., vol. 190, no. 4217, pp. 880 LP 881, Nov. 1975, doi: 10.1126/science.190.4217.880.

[34] A. Saklani and S. K. Kutty, "Plant-derived compounds in clinical trials.," Drug Discov. Today, vol. 13, no. 3-4, pp. 161171, Feb. 2008, doi: 10.1016/j.drudis.2007.10.010.

[35] F. Shahidi and X. Han, "Encapsulation of food ingredients," Crit. Rev. Food Sci. Nutr., vol. 33, no. 6, pp. 501-547, Jan. 1993 doi: 10.1080/10408399309527645.

[36] Available from: http://www.apps.who.int/medicinedocs/ en/d/Js7916e/7.12.html., "No Title," vol. 2015.

[37] E. Marin, M. I. Briceño, and C. Caballero-George, "Critical evaluation of biodegradable polymers used in nanodrugs.," Int. J. Nanomedicine, vol. 8, pp. 3071-3090, 2013, doi: $10.2147 /$ IJN.S47186.

[38] M. A. Augustin and Y. Hemar, "Nano- and micro-structured assemblies for encapsulation of food ingredients.," Chem. Soc. Rev., vol. 38, no. 4, pp. 902-912, Apr. 2009, doi: $10.1039 / \mathrm{b} 801739 \mathrm{p}$.

[39] Honkgkee Sah, Melissa Smith, Rey Chern (1996) A novel method of preparing PLGA microcapsules utilizing methylethyl ketone. Pharmaceutical Research, Vol 13, No 3, 1996, 360-365.

[40] Mandal, Sanchita \& Kumar, S. \& Krishnamoorthy, Balakrishnam \& Basu, Sanat. (2010). Development and evaluation of calcium alginate beads prepared by sequential and simultaneous methods. Brazilian Journal of Pharmaceutical $\quad$ Sciences. 465 . 493. 10.1590/S1984-82502010000400021.

[41] George A. Romar, Thomas S. Kupper, Sherrie J. Divito, Research Techniques Made Simple: Techniques to Assess Cell Proliferation, Journal of Investigative Dermatology, Volume 136, Issue 1, 2016, Pages e1-e7.

[42] Meindl Claudia, Öhlinger Kristin, Ober Jennifer, Roblegg Eva, Fröhlich Eleonore, Comparison of fluorescence-based methods to determine nanoparticle uptake by phagocytes and non-phagocytic cells in vitro, Toxicology, Volume 378, 2017, Pages 25-36.

[43] Fischer AH, Jacobson KA, Rose J, Zeller R. Hematoxylin and eosin staining of tissue and cell sections. CSH Protoc. 2008 May 1; 2008: pdb. prot 4986. doi: 10.1101/pdb.prot4986. PMID: 21356829.

[44] Riss TL, Moravec RA, Niles AL, et al. Cell Viability Assays. 2013 May 1 [Updated 2016 Jul 1]. In: Markossian S, Sittampalam GS, Grossman A, et al., editors. Assay Guidance Manual [Internet]. Bethesda (MD): Eli Lilly \& Company and the National Center for Advancing Translational Sciences; 2004-. Available from: https://www.ncbi.nlm.nih.gov/books/NBK144065/.

[45] Rahbar Saadat Y, Saeidi N, Zununi Vahed S, Barzegari A, Barar J. An update to DNA ladder assay for apoptosis detection. Bioimpacts. 2015; 5 (1): 25-28. doi: 10.15171/bi.2015.01

[46] F. Ahsan, I. P. Rivas, M. A. Khan, and A. I. Torres Suarez, "Targeting to macrophages: role of physicochemical properties of particulate carriers--liposomes and microspheres--on the phagocytosis by macrophages.," J. Control. Release, vol. 79, no. $1-3$, pp. 29-40, Feb. 2002, doi: 10.1016/s0168-3659(01)00549-1.

[47] S. Galindo-Rodriguez, E. Allémann, H. Fessi, and E. Doelker, "Physicochemical parameters associated with nanoparticle formation in the salting-out, emulsification-diffusion, and nanoprecipitation methods.," Pharm. Res., vol. 21, no. 8, pp. 1428-1439, Aug. 2004, doi: 10.1023/b:pham.0000036917.75634.be.

[48] O. I. Corrigan and X. Li, "Quantifying drug release from PLGA nanoparticulates.," Eur. J. Pharm. Sci. Off. J. Eur. Fed. Pharm. Sci., vol. 37, no. 3-4, pp. 477-485, Jun. 2009, doi: 10.1016/j.ejps.2009.04.004.

[49] X. Song et al., "Dual agents loaded PLGA nanoparticles: systematic study of particle size and drug entrapment efficiency.," Eur. J. Pharm. Biopharm. Off. J. Arbeitsgemeinschaft fur Pharm. Verfahrenstechnik e. V, vol. 69 , no. 2, pp. 445-453, Jun. 2008, doi: 10.1016/j.ejpb.2008.01.013.

[50] R. M. Mainardes and R. C. Evangelista, "PLGA nanoparticles containing praziquantel: effect of formulation variables on size distribution.," Int. J. Pharm., vol. 290, no. 1-2, pp. 137-144, Feb. 2005, doi: 10.1016/j.ijpharm.2004.11.027.

[51] X. Song et al., "PLGA nanoparticles simultaneously loaded with vincristine sulfate and verapamil hydrochloride: Systematic study of particle size and drug entrapment efficiency," Int. J. Pharm., vol. 350, pp. 320-329, Mar. 2008, doi: 10.1016/j.ijpharm.2007.08.034.

[52] M. D. Blanco and M. J. Alonso, "Development and characterization of protein-loaded poly(lactide-co-glycolide) nanospheres," Eur. J. Pharm. Biopharm., vol. 43, no. 3, pp. 287-294, 1997 https://doi.org/10.1016/S0939-6411(97)00056-8.

[53] C. Gómez-Gaete, N. Tsapis, M. Besnard, A. Bochot, and E. Fattal, "Encapsulation of dexamethasone into biodegradable polymeric nanoparticles.," Int. J. Pharm., vol. 331, no. 2, pp. 153-159, Mar. 2007, doi: 10.1016/j.ijpharm.2006.11.028. 